\title{
EducaÇão da Criança de Zero a Três Anos e EducaÇáo Especial: uma Leitura Crítica dos Documentos Que Norteiam a EducaÇão Básica ${ }^{\mathbf{1}}$ ZERo-To-Three-Year-Old ChILDREN EDUCATION AND SPECIAL EDUCATION: A Critical Analysis of Documents Guiding Preschool EduCATION
}

\author{
Fabiana Cristina Frigieri de VITTA ${ }^{2}$ \\ Carla Cilene Baptista da SILVA ${ }^{3}$ \\ Leandro Osni ZANIOLO ${ }^{4}$
}

\begin{abstract}
RESUMO: a creche que oferece uma educação de qualidade tem importante papel na promoção do desenvolvimento. A creche, enquanto parte da educação básica, deve incorporar a Educação Especial dando oportunidades educacionais às crianças com deficiência, transtornos globais do desenvolvimento e altas habilidades/superdotação. Após leitura crítica dos documentos oficiais que norteiam a educação básica, objetivamos responder às seguintes questôes: como a creche é tratada nesses documentos? Eles têm garantido o atendimento a modalidade Educação Especial nessa fase? Que contribuiçóes são ainda necessárias para que a educação na creche atenda de maneira eficiente a todas as crianças? Verificamos a falta de referência à faixa etária de zero a três anos e ao atendimento ao público da Educaçáo Especial. São vários os fatores que interferem para a qualidade da Educação Infantil que contemple a educação para todos, dentre eles conceituais, de recursos físicos, materiais e humanos. Portanto, há necessidade de discutir o papel da creche e da Educação Especial nessa fase, garantindo os pressupostos que visam proporcionar desenvolvimento integral a todas as crianças.
\end{abstract}

PALAVRAS-CHAVE: Educação Especial. Políticas Públicas. Educação Infantil. Creche.

\begin{abstract}
Nursery schools that offer quality education have an important role in promoting the development of 0-to-3year-old children. The nursery school, as part of preschool education, must incorporate special education, providing educational opportunities to children with disabilities, global developmental disorders and giftedness. After a critical analysis of official documents that guide preschool education, we aimed to answer to the following questions: how is the nursery school portrayed and treated in these documents? Have they secured special education services at this stage? What kind of contributions are still needed for education in nursery schools to be efficient to all children? We verify the absence of references to the 0 -to-3 year-old group and special education service. There are several factors which contribute to the quality of early childhood education that promote education for all, such as conceptual factors, physical, human and material resources. There is a need to discuss the role of nursery schools and special education at this stage, ensuring presumptions aimed to provide integral development for all children.
\end{abstract}

KEYWORDS: Especial Education. Public Policies. Preschool Education. Nursery School.

\section{INTRODUÇÁO}

Educação da criança de zero a três anos é um tema recorrente na atualidade quando se discute uma educaçáo de qualidade para todos. Defendemos a tese que há necessidade de maior atenção às crianças dessa faixa etária, por representar uma etapa fundamental ao desenvolvimento e assimilação de aprendizagens básicas imprescindíveis a elas. Além disso, é uma

\footnotetext{
${ }^{1}$ http://dx.doi.org/10.1590/S1413-65382216000100002

${ }^{2}$ Doutora em Educação Especial, Professora Assistente do Departamento de Educação Especial, Faculdade de Filosofia e Ciências, Unesp, Campus de Marília. Marília, SP, Brasil. fabianavitta@gmail.com

${ }^{3}$ Doutora em Psicologia Escolar e do Desenvolvimento, Professora Adjunto do Departamento de Saúde, Educação e Sociedade, Universidade Federal de São Paulo, Campus Baixada Santista. Santos, SP, Brasil.carlaci@gmail.com

${ }^{4}$ Doutor em Educação, Professor Doutor do Departamento de Psicologia da Educação, Faculdade de Ciências e Letras, Unesp, Campus de Araraquara. Araraquara, SP, Brasil.zaniolo@fclar.unesp.br
} 
fase que possibilita a inclusão das crianças com deficiência, transtornos globais do desenvolvimento e altas habilidades/superdotação (BRASIL, 2013), uma vez que poderão mostrar necessidades específicas após estarem frequentando essas instituiçóes, considerando que o façam logo aos quatro meses (VITTA, 2010; VITTA; VITTA, 2012).

Mais que isso, essa é uma fase que tem importante papel na promoção do desenvolvimento e prevenção de deficiências, não só para a criança com fatores de risco biológicos, mas principalmente para aquelas que se encontram em situação de vulnerabilidade social (LIMA; BHERING, 2006; CAMPOS et al., 2011a; BRASIL, 2009a; NUNES; CORSINO; DIDONET, 2011;VITTA; VITTA, 2012).

Campos et al. (2011a) realizaram pesquisa sobre a qualidade da Educação Infantil em seis capitais do Brasil partindo do pressuposto que a frequência a uma creche ou pré-escola de qualidade faz a diferença na vida das crianças não só no que se refere à sua trajetória escolar posterior, mas também, e principalmente, no que diz respeito o uma plena vivência de sua infância.

Rosemberg (2012) destaca a necessidade de se olhar para essa fase da educação, bastante negligenciada nas políticas públicas e analisa a dificuldade que se tem em incorporar a atenção para a criança de zero a três anos na agenda de discussóes sobre direitos e deveres.

Dessa forma, é importante que os documentos oficiais garantam um trabalho de qualidade nas creches, com cuidado especial para as diferenças provenientes de deficiências já instaladas e de condiçóes sócio-econômicas e culturais diversas. Sobretudo quando tratamos do atendimento a pessoas com deficiência, transtornos globais do desenvolvimento e altas habilidades/superdotação, há necessidade de conhecimentos específicos, adaptaçóes dos espaços físicos e materiais diferenciados, de forma a responder às diversas demandas das crianças (BRANDÃO; FERREIRA, 2013).

A educação básica incorporou à Educação Infantil o atendimento da criança de zero a três anos - denominado creche - desde a Lei de Diretrizes e Bases (LDB) promulgada em 1996. Observa-se, como destaca o relatório contido nas Diretrizes Curriculares Nacionais Gerais para a Educação Básica (BRASIL, 2013), que entre 2000 e 2008 houve uma redução de 20,6\% da matrícula na Educação Infantil, com o crescimento expressivo de 47,7\% na creche. Esse dado é estimulante, mas temos que considerar que a atenção a essa faixa etária da Educação Infantil encontra-se ainda incipiente na maioria dos municípios do país, pois não há consenso sobre como ela deve organizar-se (BRASIL, 2009a; CORREA, 2011; ROSEMBERG, 2012) e, muito menos, de uma concepção mais generalizada por parte da sociedade, de que a criança de zero a três anos deva estar inserida no contexto educacional.

Esse dado é ainda mais reforçado por Rosemberg (2012) que relata uma divisão entre creche e pré-escola, pois esta última tem se institucionalizado a ponto de ganhar um formato muito próximo ao Ensino Fundamental, enquanto o atendimento à criança de zero a três anos continua desvalorizado, inclusive com a possibilidade de substituição das creches por "políticas familiaristas para bebês" (creches domiciliares e programas de educação de mães). A autora destaca certa "[...] relutância de se lhes dar visibilidade, de se integrar a creche ao sistema educacional, de tirá-la da informalidade, de se investir em sua universalização (que não significa obrigatoriedade)" (p.12). 
Incluamos aqui, as crianças com deficiência, transtornos globais do desenvolvimento e altas habilidades/superdotação que poderão não ser atendidas adequadamente ou ser completamente excluídas dessa rede, passando para os já valorizados tratamentos especiais. Ou seja, um caminho na contramão do "politicamente correto" e do desejável.

Entendamos aqui que há um movimento em prol da educação inclusiva, que segundo a Política Nacional da Educação Especial na Perspectiva da Educação Inclusiva (BRASIL, 2008) é:

[...] uma ação política, cultural, social e pedagógica, desencadeada em defesa do direito de todos os alunos de estarem juntos, aprendendo e participando, sem nenhum tipo de discriminaçáo. A educação inclusiva constitui um paradigma educacional fundamentado na concepção de direitos humanos, que conjuga igualdade e diferença como valores indissociáveis, e que avança em relação à ideia de equidade formal ao contextualizar as circunstâncias históricas da produção da exclusão dentro e fora da escola (p.1).

Há uma preocupação real com as crianças nessa idade por sua susceptibilidade a diferentes fatores que podem interferir no desenvolvimento, tanto em nível biológico como social. Observa-se que a preocupação com as crianças em risco social ou vulneráveis socialmente tem crescido e que, sob esse aspecto, a creche tem sido considerada importante dispositivo para prevenção de riscos e promoção da qualidade de vida. Assim, compactuamos com Campos (2013) que destaca que a Educação Infantil deve ser considerada um direito de todas as crianças de acesso à cidadania e não como uma ferramenta que exima das autoridades a responsabilidade pela organização de políticas estruturais que foquem as desigualdades sociais.

Justifica-se, portanto, o objetivo deste texto, qual seja, o de lançar um olhar aos textos oficiais buscando referências à creche e à Educação Especial nessa faixa etária. Para tanto, foram lidos os principais documentos que norteiam a educação básica, conforme recomendado na apresentação da Secretaria de Educação Básica do Ministério da Educação - $(\mathrm{MEC})^{5}$ :

Atualmente, os documentos que norteiam a educação básica são a Lei no 9.394, que estabelece as Diretrizes e Bases da Educação Nacional (LDB), as Diretrizes Curriculares Nacionais para a Educação Básica e o Plano Nacional de Educação, aprovado pelo Congresso Nacional em 26 de junho de 2014.

Dessa forma, foram lidas as leis referentes à educação em nosso país que incluem a Educação Infantil, parte do nível escolar educação básica, e a Educação Especial, enquanto modalidade de educação escolar (BRASIL, 2010a): a) Lei de Diretrizes e Bases da Educação Nacional (Lei 9.304/96) - LDB (BRASIL, 2010a), juntamente com a redação reformulada pela Lei no 12.796, de 2013; b) Plano Nacional de Educação - PNE - 2000-2010 (BRASIL, 2001a); c) Lei no 13.005 - PNE (BRASIL, 2014). Em relação às Diretrizes Curriculares Nacionais para a Educação Básica (BRASIL, 2013), demos ênfase aos documentos que a compóe: Diretrizes Nacionais para a Educação Especial na Educação Básica (BRASIL, 2001b); Diretrizes Curriculares Nacionais para a Educação Infantil (BRASIL, 2010b). Somado a esses documentos, fizemos a leitura do Referencial Curricular Nacional para a Educação Infantil (BRASIL, 1998), que por muito tempo e ainda hoje, é tido como referência em muitas insti-

${ }^{5}$ Disponível em: <http://portal.mec.gov.br/secretaria-de-educacao-basica/apresentacao>. 
tuições de Educação Infantil. No decorrer das análises realizadas, outros textos se somaram para auxiliar na discussão e entendimento da problemática aqui tratada.

Durante as leituras, buscou-se responder às seguintes questóes: como a creche é tratada nesses documentos? Eles têm garantido o atendimento a modalidade Educação Especial nessa fase? Que contribuiçóes são ainda necessárias para que a educação na creche atenda de maneira eficiente a todas as crianças?

É importante destacar que ao fazermos a discussão no nosso estudo, adotamos a terminologia usada hoje nos documentos mais atuais para o público da Educaçáo Especial: deficiência, transtornos globais do desenvolvimento e altas habilidades/superdotação (BRASIL, 2013). No entanto, ao fazermos a discussão de nossos achados, usamos a terminologia própria de cada documento lido. As questóes referentes às diferentes denominaçóes dadas ao público-alvo da Educação Especial estão muito bem discutidas no trabalho de Harlos, Denari e Orlando (2014), não sendo objeto de nossa análise.

\section{SOBRe O CONCEITO DE CRECHE E DE ATENDIMENTO À CRIANÇA DE ZERO A TRÊS ANOS}

Todos os documentos analisados mostram consenso em relação à definição para a Educação Infantil. Segundo a Lei de Diretrizes e Bases da Educação (Lei 9.394) de 1996, a Educação Infantil, como parte integrante da educação básica, tem por finalidade o “[...] desenvolvimento integral da criança até cinco anos, em seus aspectos físico, psicológico, intelectual e social, complementando a ação da família e da comunidade" (BRASIL, 2010a, p.25) e é dividida em faixas etárias, ou seja, creche para as crianças de zero a três anos e pré-escola para as de quatro a cinco anos. Esta lei teve várias complementaçóes, dentre elas a Lei no 11.700/2008, que fixa como dever do Estado a garantia de vaga em escola pública de Educação Infantil a toda criança a partir dos quatro anos. Ainda que não obrigue as famílias à matrícula, garante-as àquelas que desejem vagas para essa faixa etária, o que representa, em certa medida, outro avanço na democratização da educação no Brasil.

Os Referenciais Curriculares Nacionais para a Educação Infantil (RCNEI) se colocam como uma proposta aberta, flexível e não obrigatória que tem por objetivo auxiliar na construção das propostas pedagógicas e currículos escolares, respeitando o cotidiano das instituições. Entretanto, conforme afirmam Amorim e Dias (2012), os referenciais têm sido criticados e substituídos pelas Diretrizes Curriculares Nacionais para a Educação Infantil (DCNEI), de 2009.

Segundo Amorim e Dias (2012), o MEC publicou os Referenciais numa tentativa de dirigir a forma como os currículos seriam instituídos nas instituiçóes e desrespeitou o debate que estava acontecendo sobre como seria a organização pedagógica dessa fase da educação. Tanto que em 1999, foi publicado as DCNEI que posteriormente foram revistas, em 2009.

Ainda assim, os RCNEI têm importante papel na discussão das práticas e no estabelecimento de uma melhor compreensão acerca da educação da criançade zero a três anos e têm sido usados como norteadores por várias instituições para auxiliar na sua organização. Os RCNEI definem objetivos gerais para a Educação Infantil (BRASIL, 1998). Nesses objetivos, reúnem as ideias de cuidar de si e do outro baseadas em uma concepção de aprendizagem pautada pela descoberta e pela experiência. Para que essa proposta seja colocada em prática, há 
que se proporcionar ambientes que admitam a interação entre as crianças e destas com os profissionais, recursos físicos e materiais que permitam a realização de atividades que estimulem a auto-expressão e o interesse individual e/ou coletivo dos participantes, assim como pessoal qualificado para lidar com as necessidades e capacidades da criança inserida nesse meio.

As Diretrizes Curriculares Nacionais Gerais para a Educação Básica (DCNGEB) baseiam-se na LDB e são fixadas pelo Conselho Nacional de Educação (CNE). Entraram em vigor em 2010 e,[...] visam estabelecer bases comuns nacionais para a Educação Infantil, o Ensino Fundamental e o Ensino Médio, bem como para as modalidades com que podem se apresentar, a partir das quais os sistemas federal, estaduais e municipais, por suas competências próprias e complementares, formularão as suas orientações assegurando a integração curricular das três etapas sequentes desse nível da escolarização, essencialmente para compor um todo orgânico (BRASIL, 2013, p.8).

Em todo o texto há ênfase na educação como ferramenta essencial para o desenvolvimento individual e da coletividade. Salienta a necessidade de considerar as dimensóes do cuidar e do educar como indissociáveis, desde a Educação Infantil estendendo-se para o Fundamental, Médio e níveis de ensino posteriores.

$\mathrm{Na}$ discussão da relação entre cuidado e educação, mostra a necessidade de articulação entre a esfera educacional e a social, a família e a comunidade para a formação de pessoas que saibam pensar crítica, autônoma e eticamente, considerando a globalidade das dimensóes que compóem a sociedade. Destaca a necessidade social da escola ou da educação como um processo de socialização da cultura, possibilitando o desenvolvimento dos sujeitos das aprendizagens. Salienta a obrigatoriedade da matrícula da criança na rede educacional a partir dos seis anos de idade e a necessidade de garantia de permanência na escola para essa criança.

O documento trata da organização curricular e das etapas da educação básica, reafirmando que a Educação Infantil engloba a creche (até três anos e 11 meses) e a pré-escola, com duração de dois anos.

Na seção dedicada à Educação Infantil, o artigo 22 define como objetivo os mesmos descritos pela LDB. Nos parágrafos $1^{\circ}$ e $2^{\circ}$, refere-se à diversidade da população possível na fase da Educação Infantil, pois destaca que as crianças, "[...] independentemente das diferentes condiçóes físicas, sensoriais, intelectuais, linguísticas, étnico-raciais, socioeconômicas, de origem, de religião, entre outras [...]" devem ser acolhidas e ter "atenção intensiva dos profissionais da educação" respeitando-se os "princípios da individualidade, igualdade, liberdade e pluralidade”. Ressalta ainda, a necessária relação com a família, dos agentes sociais e da sociedade para a solução de problemas "[...] respeitando os limites e as potencialidades de cada criança e os vínculos desta com a família ou com o seu responsável direto” (BRASIL, 2013, p.70).

Para entender melhor a organização relativa à Educação Infantil, mais especificamente à creche, vamos olhar o capítulo destinado à Revisão das Diretrizes Curriculares Nacionais para a Educação Infantil, aprovada em novembro de 2009 e que permite a fixação das Diretrizes Curriculares Nacionais para a Educação Infantil (DCNEI), em dezembro de 2009. Esta última incorpora o texto da primeira na forma de Lei, com artigos e parágrafos que depois são sim- 
plificados e publicados para o público em geral em 2010, disponível nas Publicaçôes da página do $\mathrm{MEC}^{6}$. Define que,

[...] As Diretrizes Curriculares Nacionais para a Educação Infantil, de caráter mandatório, orientam a formulação de políticas, incluindo a de formação de professores e demais profissionais da Educação, e também o planejamento, desenvolvimento e avaliação pelas unidades de seu Projeto Político-Pedagógico e servem para informar as famílias das crianças matriculadas na Educação Infantil sobre as perspectivas de trabalho pedagógico que podem ocorrer (BRASIL, 2013, p.83).

Reafirma as Leis anteriores: Constituição Federal de 1988 e LDB de 1996. Mostra as especificidades e necessidades dessa faixa etária e de sua relação com as necessidades familiares e sociais da atualidade, mas reafirma que, embora deva ter uma necessária articulação com outras áreas, como social e saúde, tem características e definição própria enquanto uma instituição educacional:

As creches e pré-escolas se constituem, portanto, em estabelecimentos educacionais públicos ou privados que educam e cuidam de crianças de zero a cinco anos de idade por meio de profissionais com a formação especifica legalmente determinada, a habilitação para o magistério superior ou médio, refutando assim funçôes de caráter meramente assistencialista, embora mantenha a obrigação de assistir às necessidades básicas de todas as crianças (BRASIL, 2013, p.84, grifo nosso).

Os grifos do parágrafo acima são nossos, pois esse trecho aponta uma série de especificidades da educação em creche que ainda não são respeitadas, causam muitas dúvidas e resultam em formas de atendimento bastante diferenciadas. Quando dizemos atendimentos diferenciados, não estamos nos referindo às adequações curriculares incentivadas para cada localidade e suas características peculiares. Falamos de práticas no atendimento à criança de zero a três anos que não conseguem unir a educação e o cuidado, que não possuem os profissionais com formação e que continuam a ter função meramente assistencialista. Isso vale para a rede pública e para a privada.

O documento ainda reconhece que a Educação Infantil no Brasil não tem cumprido sua função sócio-política e pedagógica e que permite a segregação e a exclusão pelos diferenciais de qualidade e atuação nesses espaços, mas organiza-se para que isso deixe de acontecer e que a instituição educacional cumpra com seu papel. Nesse sentido o currículo, ou o "[...] conjunto de práticas que buscam articular as experiências e os saberes das crianças com os conhecimentos que fazem parte do patrimônio cultural, artístico, científico e tecnológico” (BRASIL, 2013, p.86) deve ser construído coletivamente na própria unidade, com a participação de toda a comunidade de modo a possibilitar o desenvolvimento integral da criança e seu acesso aos bens sociais.

Novamente o documento afirma a indissociabilidade entre cuidado e educação, dando ao cuidado ênfase nas questóes da afetividade, intimidade, experiências corporais e autonomia. Não há nenhuma relação com a aprendizagem motora - aquisição de postura - própria da idade.

\footnotetext{
${ }^{6}$ Disponível em: <http://portal.mec.gov.br/index.php?option=com_content\&view=article\&id=12579\%3Aeducacao-infantil\&Itemid $=1152>$.
} 
Outro documento a ser analisado e que foi aprovado recentemente - Lei No 13.005, de 25 de junho de 2014 (BRASIL, 2014) - é a o Plano Nacional de Educação (PNE) para o período referente aos próximos 10 anos, a partir da data de publicação.

A nova versão do PNE (BRASIL, 2014) também não resolve esses problemas. De forma diferente do documento anterior, mas tratando dos mesmos assuntos, traz 20 metas que permitam a valorização do magistério e a melhoria na qualidade da educação com a universalização do atendimento escolar. O Artigo $8^{\circ}$ destaca que os Estados, o Distrito Federal e os Municípios devem elaborar ou adequar seus planos de educação em "[...] consonância com as diretrizes, metas e estratégias previstas neste PNE, no prazo de um ano contado da publicação desta Lei”. Quanto à Educação Infantil, apresenta já na meta 1,

[...] universalizar, até 2016, a educação infantil na pré-escola para as crianças de 4 (quatro) a 5 (cinco) anos de idade e ampliar a oferta de educação infantil em creches de forma a atender, no mínimo, 50\% (cinquenta por cento) das crianças de até 3 (três) anos até o final da vigência deste PNE.

Uma análise detalhada e contextualizada das estratégias listadas para atingir essa meta, destacando a colaboração entre a União, os Estados e os Municípios para expansão da rede pública de Educação Infantil de qualidade, garantindo estrutura física e material, além de recursos humanos com formação adequada, tanto inicial como continuada. Verifica-se que a preocupação com o aumento no número de atendimentos à população de zero a três anos é grande, sendo que em vários momentos está vinculada à renda e a riscos sociais, ressaltando inclusive a necessidade de trabalho conjunto das áreas de educação, saúde e assistência social.

Cabe-nos aqui salientar que, embora esse documento desvele alguns avanços, inclusive em maior conexão com as necessidades atuais da Educação Infantil não auxilia ou garante contribuiçóes sobre aspectos específicos da fase considerada nesse texto - zero a três anos, ou seja, não acrescenta ao PNE do decênio anterior.

Dessa forma, nos cabe analisar alguns aspectos do PNE de 2001, que colocou as metas e estratégias para a educação no período de 2001 a 2010, já que muitas instituiçóes ainda apresentam sua configuração baseada nele. No tema Educação Infantil admite que,

[...] ela estabelece as bases da personalidade humana, da inteligência, da vida emocional, da socialização. As primeiras experiências da vida são as que marcam mais profundamente a pessoa. Quando positivas, tendem a reforçar, ao longo da vida, as atitudes de autoconfiança, de cooperaçáo, solidariedade, responsabilidade. As ciências que se debruçam sobre a criança nos últimos cinqüenta anos, investigando como se processa o seu desenvolvimento, coincidem em afirmar a importância dos primeiros anos de vida para o desenvolvimento e aprendizagem posteriores. E têm oferecido grande suporte para a educaçáo formular seus propósitos e atuação a partir do nascimento (BRASIL, 2014, p.40).

Além disso, faz um diagnóstico da situação da educação nessa faixa etária, levando em consideração a dualidade cuidado e educação, assim caracterizada por se relacionar, historicamente, ao atendimento de demanda social relativa às famílias pobres, cujos pais trabalham fora de casa. Apesar de referir-se a década passada, a situação pouco mudou. 
Ressalta que a Educação Infantil é direito de toda a criança e dever do Estado, mas não é obrigatória e nem prioridade constitucional, ficando sua oferta, diante dessa realidade, concedida prioritariamente às crianças de famílias de menor renda. Essa premissa não fica clara no novo PNE, no entanto é a realidade da grande maioria das instituiçóes que atendem à criança de zero a três anos, ou seja, há seleção para entrada na creche baseada nos critérios de renda e necessidade da mãe por estar trabalhando, principalmente. Com isso, a exclusão nessa fase da educação ainda é muito grande, configurando-se não como um direito da criança, mas como assistência a ser oferecida mediante as características socioeconômicas da família.

Campos (2013) mostra que esse entendimento responde politicamente a interesses de compensação de carências, presente nas concepçóes de Educação Infantil,

[...] No Brasil, a educação da infância surge como uma política assistencial associada ao processo civilizatório que teve por base as necessidades individuais e não coletivas, evidenciando as responsabilidades individuais e não a questão do direito social. A concepçáo de educaçáo infantil como estratégia civilizatória e assistencial retira-a da universalidade inclusiva e acaba por conferir-lhe um papel de compensar carências, isto é, ela acaba sendo uma forma de agir sobre os efeitos da pobreza, mas nẫo sobre suas causas (p.202).

Campos (2013) faz um importante estudo a respeito da forma como a Educação Infantil tem sido entendida no Brasil, a partir da análise das orientaçóes contidas em documentos produzidos pela UNESCO e UNICEF para educação da criança de zero a seis anos. Mostra de forma muito clara que o governo usa a ideia de "educação para todos" de forma paliativa, deixando para trás as verdadeiras (ou efetivas) políticas sociais que permitiriam melhor qualidade de vida para todos e jogando na educação um papel de proporcionar ferramentas para que cada um busque melhorar sua própria qualidade de vida. Segundo a autora, esse tipo de organização política sobre a educação leva à exclusão, pois oferece um serviço de baixa qualidade e "[...] com baixo potencial para um desenvolvimento integral e adequado das crianças" (CAMPOS, 2013, p.203).

[...] Desse modo, em nome da inclusão social, do alívio da pobreza, da maior eficácia e eficiência das açóes estatais, observamos a emergência de uma nova segmentação que resulta, ao final, em exclusão justamente da população que, de acordo com os discursos oficiais, deveria ser incluída na sociedade. De acordo com o que discutimos, as políticas focais não oportunizam aos sujeitos integração efetiva na sociedade; pelo contrário, acabam reforçando a assistência, no sentido mais tradicional e, mantendo tal população na dependência (CAMPOS, 2013, p.206).

Comungamos com vários estudiosos na área de Educação Infantil (CAMPOS et al., 2011a; ROSEMBERG, 2012; VITTA; VITTA, 2012), especialmente da creche, que explicitam que o aumento do número de instituiçóes, incentivado pelo governo, não é garantia dessa qualidade, pois aspectos de financiamento e formação de recursos humanos devem receber atenção especial, assim como a identificação das diferentes realidades para o direcionamento de políticas que respeitem o direito da criança à educação qualificada, acesso à cultura e condiçóes de vida que beneficiem seu desenvolvimento global. 


\section{CONCEPÇÓES ACERCA DA EDUCAÇÃo ESPECIAL NA CRECHE}

Seria fácil supormos que a inserção da criança com deficiência, transtornos globais do desenvolvimento e altas habilidades/superdotação é natural nesse contexto de conceituações sobre Educação Infantil, devendo ser tratada conjuntamente no decorrer dos documentos. Não é isso o que acontece.

Em relação à Educação Especial, a LDB a define como uma "[...] modalidade de educação escolar oferecida preferencialmente na rede regular de ensino, para educandos com deficiência, transtornos globais do desenvolvimento e altas habilidades ou superdotação" (redação reformulada pela Lei no 12.796 , de 2013) ${ }^{7}$. Tem início na faixa etária de zero a cinco anos, durante a Educação Infantil e indica que o aluno deve ser encaminhado para classes, escolas ou serviços especializados, somente quando as condiçóes específicas do educando o exigirem, sendo que não define o que seriam essas condiçóes especiais.

Trata da concepção de currículos, métodos, técnicas e recursos educativos diferenciados para a Educação Especial, de adaptaçóes que permitam ao educando completar o Ensino Fundamental, em virtude de suas características especiais. Prioriza o atendimento na rede pública regular de ensino; mas, preocupado com a formação dos professores para lidar com esse público, indica a colaboração de instituiçóes privadas, sem fins lucrativos, especializadas na área, com auxílio técnico e financeiro do poder público. Não se reporta à formação do professor para a Educação Especial.

Minto (2002) faz uma análise desse texto, concluindo ser ele pouco esclarecedor, ficando em aberto o compromisso do poder público com a educação de indivíduos com deficiências, transtornos globais do desenvolvimento e altas habilidades/superdotação e não concebendo a Educação Especial com os mesmos objetivos da educação geral. Segundo o autor, uma análise do texto da LDB sugere que a Educação Especial não está totalmente assumida pelo governo, que poderá destinar recursos à iniciativa privada para o atendimento dessa clientela. Mendes (2006) salienta que embora as leis (Constituição Federal de 1998 e LDB) estabeleçam o atendimento especializado preferencialmente na rede regular de ensino, "[...] não define obrigatoriedade e até admite a possibilidade de escolarização que não seja na escola regular” (p.398).

Em relação à inclusão das crianças com deficiências, transtornos globais do desenvolvimento e altas habilidades/superdotação na Educação Infantil, apesar de garantir o início da Educação Especial já nesse nível, deixa em aberto como isso deve ocorrer.

Os RCNEI reportam-se à educação de crianças "portadoras de necessidades especiais", ou seja, "portadoras de deficiência, de condutas típicas e de altas habilidades" (BRASIL, 1998, p.36) no volume de introdução, sendo que no desenvolvimento dos eixos de trabalho nada é referido. Isso pode gerar duas formas de entendimento: na primeira, é possível imaginar que esta criança não é levada em consideração por não ser realidade a sua inserção na maioria das instituiçóes. Sendo assim, não há necessidade de apontar qualquer tipo de recomendação para essa criança. Na segunda forma de pensar, mais interessante, a nosso ver, esta criança seria vista como outra criança qualquer, ou seja, com características individuais que devem ser respeitadas de modo a possibilitar que as atividades promovam seu desenvolvimento global.

${ }^{7}$ Disponível em: <http://www.planalto.gov.br/ccivil_03/leis/19394.htm> 
Para que se possa entender qual das formas é a adotada pelos RCNEI, há necessidade de uma análise mais detida no texto. Inicialmente o documento discute conceitos gerais sobre a função da Educação Infantil, considerações sobre creches e pré-escolas, criança, educar, a formação do professor, etc. No item designado como $A$ criança, o documento traz uma conceituação, na qual destaca o caráter singular do ser criança, com suas individualidades e diferenças, que devem ser respeitadas pela instituição de Educação Infantil e por seus profissionais. Aqui, já é possível encontrarmos um justificador para a ideia da criança, público-alvo da Educação Especial, estar inserida na discussão geral das atividades, já que a ela deve ser considerada com suas individualidades e diferenças.

No tópico seguinte, Educar, ressalta-se que,

[...] a instituição de educação infantil deve tornar acessível, a todas as crianças que a frequentam, indiscriminadamente, elementos da cultura que enriquecem o seu desenvolvimento e inserçáo social. Cumpre um papel socializador, propiciando o desenvolvimento da identidade das crianças, por meio de aprendizagens diversificadas, realizadas em situações de interação (BRASIL, 1998, p.23, grifo nosso).

Verificamos nessa definição o reconhecimento de uma educação que deve respeitar a individualidade de todas as crianças, criando situaçóes que promovam a socialização e que contribuam para a sua formação. Destaca que isso deve ocorrer junto às crianças que frequentam a instituição de Educação Infantil, ou seja, se há crianças com necessidades especiais incluídas, estas devem ser respeitadas e seu potencial deve ser considerado objetivando otimizar o seu desenvolvimento global.

Nesse mesmo tópico - Educar - no tema aprender em situaçóes orientadas, são incluídos vários subtemas, dentre eles, educar crianças com necessidades especiais. Cita os benefícios da convivência com a diversidade, para elas e para as crianças tidas como normais. $\mathrm{O}$ benefício para elas ocorre na,

[...] medida em que representa uma inserção de fato no universo social e favorece o desenvolvimento e a aprendizagem, permitindo a formação de vínculos estimuladores, o confronto com a diferença e o trabalho com a própria dificuldade (BRASIL, 1998, p.35).

Considera que a escola inclusiva seria o ideal no sentido de abrir espaço para todas as crianças e que o desafio é desenvolver uma pedagogia centrada na criança,

[...] capaz de educar a todas, sem discriminaçáo, respeitando suas diferenças; uma escola que dê conta da diversidade das crianças e ofereça respostas adequadas às suas características e necessidades, solicitando apoio de instituiçôes e especialistas quando isso se fizer necessário (BRASIL, 1998, p.36).

O RCNEI não apresenta diretrizes em relação a esse processo, como ressalta Mendes (2002, p.82),

[...] embora haja uma tomada de posição a favor da escola inclusiva, esta posição não foi suficientemente contemplada em pelo menos três documentos oficiais preliminares: o referencial curricular nacional para a educaçáo infantil (1998); os parâmetros curriculares nacionais para o ensino fundamental (1997); e o referencial pedagógico-curricular para a formação de professo- 
res de educação infantil e séries iniciais do ensino fundamental (1997). Nesses documentos não se menciona como os alunos com deficiência seriam atendidos na rede regular de ensino e qual o papel do professor nesse processo [...].

Nas DCNGEB (BRASIL, 2013),no artigo 21, ao tratar das etapas da educação básica, em parágrafo único, diz que os sujeitos que "fogem à norma" podem não estar nas fases ou etapas previstas para a educação básica, sendo estas tratadas em partes separadas do documento, como modalidades de ensino. Aqui há referência aos portadores de deficiência limitadora, habitantes de zonas rurais, indígenas e quilombolas, entre outros.

Esse documento, ao fazer a revisão das diretrizes curriculares nacionais para a Educação Infantil, discute no subitem oito a organização curricular e aponta objetivos e condiçôes para que a mesma ocorra. Discute a indissociabilidade entre cuidado e educação, as multiplicidades de culturas, o combate ao racismo e às discriminaçóes de todas as formas, o respeito à dignidade da criança e a garantia de experiência educacional de qualidade a todas as crianças.

Há um parágrafo que concerne ao combate ao racismo e às discriminaçóes de todas as formas, no qual se recomenda para o público-alvo da Educação Especial que:

$\mathrm{O}$ olhar acolhedor de diversidades também se refere às crianças com deficiência, transtornos globais do desenvolvimento e altas habilidades/superdotação. Também o direito dessas crianças à liberdade e à participação, tal como para as demais crianças, deve ser acolhido no planejamento das situaçóes de vivência e aprendizagem na Educação Infantil(BRASIL, 2013, p.90).

Ao ressaltar os princípios básicos da Educação Infantil - éticos, políticos e estéticos destaca a necessidade ao respeito pela diversidade e pluralismo de realidades presentes na vida das crianças, que devem ser considerados na construçáo de aprendizagens valiosas para elas.

Ainda na organização das experiências de aprendizagem, descreve vários fatores que devem ser considerados, dando exemplos de atividades. Inclui a criança com deficiências, transtornos globais do desenvolvimento e altas habilidades/superdotação chamando atenção para os espaços, materiais e atividades a serem organizados, utilizando critérios pedagógicos. A maioria das recomendaçóes liga-se ao acesso à cultura e construçấo de saberes e às diferentes linguagens, incluindo expressão motora.

Uma crítica que acreditamos ser fundamental em relaçáo a esses documentos é que, embora sejam abertos para permitir que cada instituição, cada realidade, possa adaptá-los às suas necessidades, têm suas recomendaçóes mais voltadas para as crianças maiores, com pouca referência às menores (embora apareçam mais do que nos documentos anteriores) e pressupóem uma formação bastante adequada quanto ao atendimento em pré-escola e creche. Contudo, tomando como referência a creche - nosso foco de análise neste texto - torna-se inevitável questionarmos que tipo de conhecimento é necessário que o professor tenha sobre o desenvolvimento da criança de zero a três anos? $\mathrm{E}$ da criança que ainda náo possui a linguagem oral e requer uma série de atividades de cuidado: como capacitar devidamente o docente para que ele possa levar ao desenvolvimento integral e a aprendizagem, respeitando as diferenças próprias da idade ou causadas por fatores biológicos ou ambientais?

Como ressaltam Sekkel, Zanelatto e Brandão (2010), 
[...] Estar incluído não é apenas estar presente, é também ter suas necessidades percebidas e acolhidas pelos outros, é trabalhar junto, em um ambiente permeado pela confiança, pelo cuidado e pela reflexão (p.119).

Essas questôes são importantes, pois outro tópico tratado pelo DCNGEB em relação à Educação Infantil é o processo de avaliação, que deve permitir ao professor que,

[...] Possa pesquisar quais elementos estão contribuindo, ou dificultando, as possibilidades de expressão da criança, sua aprendizagem e desenvolvimento e, então fortalecer, ou modificar, a situação, de modo a efetivar o Projeto Político-Pedagógico de cada instituição (BRASIL, 2013, p.95).

Os autores do presente texto, também reafirmam a importância de se estabelecer mecanismos de avaliação permanente por parte do professor, não apenas no sentido de corrigir rumos do processo de ensino ou das metas do projeto pedagógico a serem obtidas mas,especialmente, como forma de aprimoramento das açóes docentes diante dessa população, afim de desmistificar muitas noçóes - costumeiramente equivocadas, que permeiam os estigmas frente à pessoa com deficiência.

Voltando ao texto geral das DCNGEB, o artigo 29, trata a Educação Especial “[...] como modalidade transversal a todos os níveis, etapas e modalidades de ensino, parte integrante da educação regular, devendo ser prevista no projeto político-pedagógico da unidade escolar” (BRASIL, 2013, p.72). Garante a matrícula em classes comuns e no Atendimento Educacional Especializado (AEE), devendo ser organizado um serviço de qualidade que permita o desenvolvimento do educando, incluindo, acessibilidade, formação de professores, articulação de políticas intersetoriais.

A Educação Especial volta a ser discutida em um capítulo intitulado Diretrizes operacionais para o atendimento educacional especializado na educação básica, modalidade Educação Especial (Resolução no 04, de 2 de outubro de 2009) (BRASIL, 2009b). Muitos são os aspectos abordados nesse documento, com ênfase na transversalidade da Educação Especial e no oferecimento de AEE em horário alternativo para que a educação inclusiva seja realmente possível. Esse atendimento pode ser oferecido pela própria escola ou por instituição sem fins lucrativos, auxiliando na organização de atividades e materiais que possibilitem a aprendizagem e desenvolvimento do aluno, com a participação da família e de outros setores da sociedade. Ao se analisar o documento é possível adequar a maioria de seu texto para toda a educação básica, inclusive para a Educação Infantil. No entanto, há particularidades nessa fase da educação, principalmente tratando-se da creche, que atribuem significados especiais quando se lê sobre avaliação, adaptação e aplicação de recursos pedagógicos e de acessibilidade. $\mathrm{O}$ que podemos questionar, portanto, é: quais são essas especificidades? Quem sabe delas? Há formação suficiente para lidar com elas?

O PNE 2001-2010 (BRASIL, 2001b) faz um diagnóstico da situação relativa a essa modalidade de ensino. Explica que o sistema de informaçóes não contempla dados confiáveis e completos e que os números disponíveis indicam uma oferta extremamente baixa diante da necessidade do país, principalmente ao se considerar que a Constituição assegura a Educação Especial como direito das pessoas com necessidades especiais, preferencialmente na rede regular de ensino. 
O atual PNE (BRASIL, 2014) aponta como uma das estratégias para a meta quatro a importância em “[...] promover, por iniciativa do Ministério da Educação, nos órgãos de pesquisa, demografia e estatística competentes, a obtenção de informação detalhada sobre o perfil das pessoas com deficiência, transtornos globais do desenvolvimento e altas habilidades ou superdotação de 0 (zero) a 17 anos” o que parece confirmar a ausência de informaçóes a respeito.

A nosso ver, o atendimento aos alunos com deficiências, transtornos globais do desenvolvimento e altas habilidades/superdotação no nível da Educação Infantil é reduzido, apesar do texto enfatizar em suas diretrizes que "[...] a educação especial, como modalidade de educação escolar, terá que ser promovida sistematicamente nos diferentes níveis de ensino [...]. Por isso, o atendimento deve começar precocemente, inclusive como forma preventiva” (BRASIL, 2001b, p.86-87). No entanto, o próprio texto, talvez considerando que na Educação Infantil não há vagas para todos que a procurem, remete, de forma contraditória em nossa opinião, à educação fundamental a responsabilidade da detecção de deficiências.

É possível constatarmos que esse atendimento na creche é nomeado como estimulação precoce, criando uma ambiguidade por ser também designado, ao mesmo tempo, como modalidade de Educação Especial, o que dá a impressão de que não há inclusão da criança com deficiências, transtornos globais do desenvolvimento e altas habilidades/superdotação nessa faixa etária, ou que não existam dados que permitam um delineamento mais apurado da situação. Referente a essa fase, destaca que,

[...] certas organizaçóes da sociedade civil, de natureza filantrópica, que envolvem os pais de crianças especiais, têm, historicamente, sido um exemplo de compromisso e de eficiência no atendimento educacional dessa clientela, notadamente na etapa da educação infantil. [...] justifica-se, portanto, o apoio do governo a essas instituiçóes como parceiras no processo educacional dos educandos com necessidades especiais (BRASIL, 2001b, p.88).

Essa ideia é reforçada no documento Política Nacional de Educação Especial na perspectiva da Educação Inclusiva (BRASIL, 2008), no qual podemos verificar a menção específica para essa faixa etária e que reforça o atendimento educacional especializado à intervenção precoce:

Do nascimento aos três anos, o atendimento educacional especializado se expressa por meio de serviços de intervenção precoce que objetivam otimizar o processo de desenvolvimento e aprendizagem em interface com os serviços de saúde e assistência social (BRASIL, 2008, p.16).

Se por um lado, tal documento avança apontando para a necessidade de oferecer um atendimento educacional especializado e de desenvolver ações intersetoriais com intuito de buscar garantir educação para todos e em todos os níveis, por outro lado, parece remeter às áreas da saúde e da assistência social o atendimento a essas crianças e àquelas em situação de vulnerabilidade social, principalmente quando se refere a educação de zero a três anos.

Essa ideia é reforçada por Laplane e Pietro (2010) na análise dos documentos da Conferência Nacional de Educação (CONAE) 2010 que discutem diretrizes e estratégias a serem consideradas no Plano Nacional de Educação para o decênio 2011-2020. Destacam a extensão do direito à educação para crianças de zero a três anos, com integração entre os siste- 
mas de saúde e assistência social, mas não relatam maiores relaçóes entre essa faixa educacional e as propostas de Educação Especial.

A nova versão do PNE (2014) destaca no artigo oito, primeiro parágrafo,

[...] Os entes federados estabelecerão nos respectivos planos de educação estratégias que: [...] III - garantam o atendimento das necessidades específicas na educação especial, assegurado o sistema educacional inclusivo em todos os níveis, etapas e modalidades.

Na meta 1, sobre universalização da Educação Infantil coloca como estratégia,

[...] priorizar o acesso à educação infantil e fomentar a oferta do atendimento educacional especializado complementar e suplementar aos (às) alunos (as) com deficiência, transtornos globais do desenvolvimento e altas habilidades ou superdotação, assegurando a educação bilíngue para crianças surdas e a transversalidade da educação especial nessa etapa da educação básica.

No entanto, na meta quatro trata especificamente da Educação Especial, inicia seu texto garantindo às crianças acima de quatro anos atendimento escolar na rede regular de ensino. Como o próprio enunciado da meta deixa claro, pouco é dito sobre as crianças de zero a três anos, ou seja, nas estratégias repetem o que já foi dito reafirmando a necessidade do universalização de atendimento escolar a essa faixa etária com deficiência, transtornos globais do desenvolvimento e altas habilidades ou superdotação. Trata ainda da complementação no repasse do Fundeb, de recursos físicos e materiais, garantindo a acessibilidade, do atendimento educacional especializado articulado à escola inclusiva, da formação continuada de professores, da necessidade de parecerias intersetoriais e interinstitucionais (com instituiçóes comunitárias, confessionais ou filantrópicas sem fins lucrativos) para apoio no atendimento a esta população e à formação.

Nas outras metas destaca as outras fases da educação, ensino médio profissional, melhoria da qualidade da educação superior, a elevação da taxa de alfabetização e o tempo de escolaridade da população brasileira, valorização e formação para o magistério e ampliação dos investimentos do governo em educação. Na meta 15 que trata da formação do professor para a educação básica, salienta estratégias diversas para a melhora do quadro profissional nessa função, destaca a implementação de "[...] programas específicos para formação de profissionais da educação para as escolas do campo e de comunidades indígenas e quilombolas e para a educação especial".

Laplane e Pietro (2010) consideram que havia intenção de organizar um Plano Nacional de Educação para o decênio 2011-2020 com maior atenção a diferentes temas, defendidos por grupos minoritários (educação no campo, indígenas, educação quilombola, diversidade sexual, crianças em situação de risco, educação especial, dentre outros).

Essa intenção é observada na análise do PNE (2014), no entanto, não há garantias de execução das metas, que ainda é desconhecida de muitos profissionais que estão na prática, inclusive por ter sido aprovada somente em 25 de junho de 2014, ou seja, com pelo menos três anos de atraso. Esse contexto é reflexo de uma política do governo atual que, com certeza, não prioriza a educaçáo de forma adequada, principalmente a infantil e a especial. Segundo Mendes (2006, p.401), 
[...] No Brasil, no campo educacional, as perspectiva para a mudança estáo postas na lei, mas ainda não estáo devidamente traduzidas em açôes políticas, e por isso nem chegam às escolas, e menos ainda às salas de aula. $\mathrm{O}$ poder público não está cumprindo bem sua função, o que não impede que cada um assuma sua parte e se torne sujeito dessa história (p.401).

Mendes (2006) ao analisar as políticas para a inclusão escolar no Brasil destaca que as ações do MEC relacionadas ao assunto centralizam-se no local onde as crianças com necessidades educacionais especiais devem estudar, deslocando o "[...] debate de seu cerne, que seria como melhorar a qualidade da educação brasileira para todos os alunos indistintamente" (p.400).

\section{Para náo terminar a discussáo...}

A LDB é um documento que possibilitou avanço na legislação em relação à Educação Infantil, que passou a fazer parte do sistema educacional e que já passou por várias reformulaçôes buscando adequar-se à realidade apresentada nesses quase 20 anos passados. Vários autores (CORREA, 2011; ROSEMBERG, 2012) reiteram essa afirmação, mostrando que a LDB endossa outros documentos importantes, como a Constituição de 1988 e o Estatuto da Criança e do Adolescente, em relação ao reconhecimento dos direitos fundamentais da criança.

Os demais documentos vêm complementar a LDB e nela se baseiam. A análise desses textos nos permitiu verificar que há grande dificuldade na implementação de uma proposta de qualidade para a Educação Infantil que contemple a educação para todos, uma vez que existe uma gama de fatores interferindo para a organizaçáo de uma prática embasada em aspectos consistentes. Às dificuldades do processo de inclusão de crianças com deficiências, transtornos globais do desenvolvimento e altas habilidades/superdotação na creche somam-se outras, relativas a essa fase da Educação Infantil e à instituição propriamente dita, tais como seus objetivos e finalidades, definição de seus conteúdos e dinâmicas, financiamento, formação dos profissionais que nela atuam, dentre outros. Portanto, é na discussão sobre o papel da creche que se deve incluir e aprofundar a relaçáo entre a função dessa instituição com a necessidade de oferta de educação para todos, oportunizando que a finalidade garantida por lei para a Educação Infantil, no sentido de proporcionar desenvolvimento integral à criança, seja realmente colocada em prática.

Para nossa análise, relativa à creche e a Educação Especial, todo o discurso permite fundamentar a importância do acesso às instituiçóes educacionais a todas as crianças, mas trata-se ainda de um discurso incipiente ligado a essa fase da educaçáo.

Destacou-se, na análise desses documentos, a concentração de aspectos sobre a Educaçáo Especial no nível de Ensino Fundamental. A falta de referência à faixa etária de zero a três anos e ao atendimento da criança com deficiências, transtornos globais do desenvolvimento e altas habilidades/superdotação, apesar do aumento na produção de pesquisas na área da Educação Infantil e Educação Especial, não é exclusividade desses documentos, pois observamos que o tratamento dispensado nos registros em relação a esses assuntos é bastante escasso.

Ademais, problemas relacionados à infraestrutura, recursos materiais e humanos afetam diretamente a organização de uma Educação Infantil de qualidade (CAMPOS;FÜLLGRAF; WIGGERS, 2006; VITTA, 2010; CAMPOS et al., 2011a). Esses fatores têm sido citados 
como importantes para a qualidade dos serviços oferecidos pelas instituiçóes que atendem à faixa etária de zero a cinco anos.

Campos et al. (2011a, 2011b), Bassi (2011), Kagan (2011) realizaram um estudo, em 2009 e destacam que a formação do professor, a organização das instituiçóes e as leis que as orientam afetam diretamente a qualidade do serviço oferecido para a criança de zero a três anos. Esses dados são reforçados no relatório de avaliação da Educação Infantil (BRASIL, 2009). É importante que o governo se comprometa com a educação na fase da creche e com a possibilidade de acesso de todas as crianças a instituiçóes de qualidade e isso deve transparecer nos documentos de forma explícita, possibilitando a organização de políticas locais sérias e eficientes para o atendimento a esses cidadãos.

Quando se pensa em estudar a inclusão de crianças com deficiência, transtornos globais do desenvolvimento e altas habilidades/superdotação na creche e o papel dessa fase educacional na promoção do seu desenvolvimento integral, respeitando a diversidade que constitui essa clientela, é necessário que se faça um recorte da realidade levando em consideração os seus diferentes elementos constituintes: a lei, o projeto pedagógico, os profissionais, a prática propriamente dita, assim como a avaliação permanente desse processo. Apenas assim, será possível observar a existência ou não de coerência entre o que é projetado idealmente e o que acontece, o que é planejado e o que é vivido. A análise desses elementos permitirá examinar a realidade e os aspectos que a constituem e, assim, propor novas reflexóes que levem a mudanças significativas através da interferência nos pontos sobre os quais as análises demonstrem inconsistências.

É preciso que o atendimento à criança de zero a três anos deixe a dimensão assistencialista, paliativa de problemas sociais estruturais maiores e seja considerada como um direito social de todas as crianças.

\section{REFERÊNCIAS}

AMORIM, A.L.N.; DIAS, A.A. Currículo e educação infantil: uma análise dos documentos curriculares Nacionais. Espaço do Currículo, v.4, n.2, p.125-137, 2012.

BASSI, M. Financiamento da educação infantil em seis capitais brasileiras. Cadernos de Pesquisa, v.41, n.142, p.116-141, 2011.

BRANDÃO, M. T.; FERREIRA, M. Inclusão de crianças com necessidades educativas especiais na Educação Infantil. Rev. Bras. Ed. Esp., Marília, v.19, n.4, p.487-502, 2013.

BRASIL. Ministério da Educação e do Desporto. Secretaria de Educação Fundamental. Referencial curricular nacional para a educação infantil. Brasília, DF: MEC/SEF, 1998. v.1.

BRASIL. Ministério da Educação. Plano Nacional de Educação - PNE. Brasília, DF: INEP, 2001a.

BRASIL. Ministério da Educação. Ministério da Educação. Secretaria de Educação Especial. Diretrizes nacionais para a educação especial na educaçâo básica. Brasília, DF: $2001 \mathrm{~b}$.

BRASIL. Política Nacional Educação Especial na Perspectiva da Educação Inclusiva. Brasília, DF: MEC, 2008.

BRASIL. Ministério da Educação. Secretaria da Educação Básica. Politica de educação infantil no Brasil: Relatório de avaliação. Brasília, DF: MEC, SEB, Unesco, 2009a. 
BRASIL. Ministério da educação conselho nacional de educação câmara de educação básica.

Resolução no 4, de 2 de outubro de 2009. Institui diretrizes operacionais para o atendimento educacional especializado na educação básica, modalidade educação especial. Brasília, DF: 2009b. Disponível em: <http://portal.mec.gov.br/dmdocuments/rceb004_09.pdf>. Acesso em: 18 mar. 2016.

BRASIL. Lei Darcy Ribeiro (1996). LDB: Lei de Diretrizes e Bases da Educação Nacional. 5.ed. Brasília, DF: Câmara dos Deputados, Coordenação Ediçôes Câmara, 2010a.

BRASIL. Ministério da Educaçáo. Secretaria da Educação Básica. Diretrizes curriculares nacionais para a educação infantil. Brasília, DF: MEC, SEB, 2010 b.

BRASIL. Ministério da Educação. Secretaria de Educação Básica. Diretoria de Currículos e Educação Integral. Diretrizes Curriculares Nacionais Gerais da Educação Básica. Brasília, DF: MEC, SEB, DICEI, 2013.

BRASIL. Ministério da Educação. Lei no 13.005 - Plano Nacional de Educação - PNE. Brasília, DF: INEP, 2014. Disponível em: <http://fne.mec.gov.br/images/doc/pne-2014-20241.pdf>. Acesso em 03 set. 2014 .

CAMPOS, M.M.; FÜLLGRAF, J.; WIGGERS, V. A qualidade da educação infantil brasileira: alguns resultados de pesquisa.Cadernos de Pesquisa,v.36, n.127, p.87-128, 2006.

CAMPOS, M.M. et al.A qualidade da educação infantil: um estudo em seis capitais brasileiras. Cadernos de Pesquisa, v, 41, n. 142, p. 20-54, 2011 a.

CAMPOS, M. M. et al. A contribuição da educação infantil de qualidade e seus impactos no início do ensino fundamental. Educação e Pesquisa, São Paulo, v.37, n.1, p.15-33, 2011 b.

CAMPOS, R. As indicaçóes dos organismos internacionais para as políticas nacionais de educação infantil: do direito à focalização. Educação e Pesquisa, São Paulo, v.39, n.1, p.195-209, 2013.

CORREA, B.C. Educação infantil e ensino fundamental: desafios e desencontros na implantação de uma nova política. Educação e Pesquisa, São Paulo, v.37, n.1, p.105-120, 2011.

HARLOS, F.E.; DENARI, F.E.; ORLANDO, R.M. Análise da estrutura organizacional e conceitual da educação especial brasileira (2008-2013). Rev. Ed. Esp., Marília, v.20, n.4, p.497-512, 2014.

KAGAN, S.L. Qualidade na educação infantil: revisão de um estudo brasileiro e recomendaçóes. Cadernos de pesquisa, v.41, n.142, p.56-67, 2011.

LAPLANE, A.L.F.; PRIETO, R. G. Inclusão, diversidade e igualdade na CONAE 2010: perspectivas para o novo plano nacional de educação. Educ. Soc., Campinas, v.31, n.112, p.919-938, 2010.

LIMA, A.B.R.; BHERING, E. Um estudo sobre creches como ambiente de desenvolvimento. Cadernos de Pesquisa, v.36, n.129, p.573-596, 2006.

MENDES, E.G. Perspectivas para a construção da escola inclusiva no Brasil. In: PALHARES, M. S.; MARINS, S. C. (Org.). Escola inclusiva. São Carlos: EdUFSCar, 2002. p.61-85.

MENDES, E.G. A radicalização do debate sobre inclusão escolar no Brasil. Revista Brasileira de Educação, v.11, n.33, p.387-405, 2006.

MINTO, C.A. Educação especial: da LDB aos planos nacionais de educação - MEC e proposta da sociedade brasileira. In: PALHARES, M. S.; MARINS, S. C. (Org.). Escola inclusiva. São Carlos: EdUFSCar, 2002. p.11-39. 
NUNES, M.F.R.; CORSINO, P.; DIDONET, V. Educação infantil no Brasil: primeira etapa da educação básica. Brasília, DF: UNESCO, Ministério da Educação, Secretaria da Educação Básica, Fundação Orsa, 2011.

ROSEMBERG, F. A criança pequena e o direito à creche no contexto dos debates sobre infância e relaçóes raciais. In: BENTO, M. A. B. (Org.) Educaçâo infantil, igualdade racial e diversidade: aspectos políticos, jurídicos, conceituais. São Paulo: Centro de Estudos das Relaçôes de Trabalho e Desigualdades - CEERT, 2012. p.10-46.

SEKKEL, M.C.; ZANELATTO, R.; BRANDÃO, S.B. Ambientes inclusivos na educação infantil: possibilidades e impedimentos. Psicologia em Estudo, Maringá, v.15, n.1, p.117-126, 2010.

VITTA, F.C.F. A inclusão da criança com necessidades especiais na visão de berçaristas. Cadernos de Pesquisa, v.40, n.139, p.75-93, 2010.

VITTA, F. C. F.; VITTA, A. Promoção do desenvolvimento da criança no contexto educacional: o berçário. In: ZANIOLO, L. O.; DALL'ACQUA, M. J. C. (Org.). Inclusão escolar: pesquisando políticas públicas, formação de professores e práticas pedagógicas. Jundiaí: Paco Editorial, 2012. p.141-162.

Recebido em: 16/12/2014

Reformulado em: 16/09/2015

Aprovado em: 20/10/2015 